\title{
Growth inhibition by NVP-BEZ235, a dual PI3K/mTOR inhibitor, in hepatocellular carcinoma cell lines
}

\author{
MITSUHIRO MASUDA ${ }^{1,2}$, MANAMI SHIMOMURA ${ }^{1}$, KEN KOBAYASHI $^{3}$, \\ SHUJI KOJIMA $^{2}$ and TETSUYA NAKATSURA ${ }^{1}$ \\ ${ }^{1}$ Section for Cancer Immunotherapy, Investigative Treatment Division, Research Center for Innovative Oncology, \\ National Cancer Center Hospital East, Kashiwa, Chiba; ${ }^{2}$ Department of Radiation Biosciences, Faculty of \\ Pharmaceutical Sciences, Tokyo University of Science, Noda, Chiba; ${ }^{3}$ Novartis Pharma K.K. \\ Oncology Business Unit, Translational Medicine Department, Tokyo, Japan
}

Received May 17, 2011; Accepted June 16, 2011

DOI: $10.3892 /$ or.2011.1370

\begin{abstract}
Dysregulation of the phosphatidylinositol-3-kinase $(\mathrm{PI} 3 \mathrm{~K}) / \mathrm{mammalian}$ target of rapamycin (mTOR) pathway frequently occurs in human tumors, and is therefore considered to be a good molecular target for treatment. In hepatocellular carcinoma (HCC), overexpression of p-Akt and decrease of PTEN expression have been reported. NVP-BEZ235 is a novel dual inhibitor of PI3K and mTOR; however, its effect on HCC has not been documented. Consequently, we investigated the effects of NVP-BEZ235 on the PLC/PRF/5, HLE, JHH7 and HepG2 HCC cell lines in vitro and in vivo. NVP-BEZ235 decreased the levels of p-Akt and p-p70S6K and inhibited cell proliferation in all HCC cell lines in a dose-dependent manner. Flow cytometric analysis revealed that inhibition of cell proliferation by NVP-BEZ235 was accompanied by G1 arrest in all cell lines, and that NVP-BEZ235 induced apoptosis in PLC/ PRF/5 and HLE cells. Tumor growth was suppressed without body weight loss when NVP-BEZ235 was orally administered to JHH-7 tumor-bearing mice for 11 days. These results suggest that NVP-BEZ235 is a potential new candidate for targeted HCC therapy.
\end{abstract}

\section{Introduction}

Hepatocellular carcinoma (HCC) is the fifth most common cancer and the third-leading cause of cancer-related deaths worldwide (1). HCC accounts for $85-90 \%$ of all primary liver cancers. The number of new cases of liver cancer per year

Correspondence to: Dr Tetsuya Nakatsura, Section for Cancer Immunotherapy, Investigative Treatment Division, Research Center for Innovative Oncology, National Cancer Center Hospital East, 6-5-1 Kashiwanoha, Kashiwa, Chiba 277-8577, Japan

E-mail: tnakatsu@east.ncc.go.jp

Key words: NVP-BEZ235, PI3 kinase, rapamycin, Akt, hepatocellular carcinoma has increased in many countries over the last several decades (2). Despite improvements in chemotherapy, liver resection, transcatheter arterial chemoembolization (TACE) and transplantation, many HCC patients still experience recurrence or progression after treatment. In addition, HCC is generally recognized as being chemoresistant. Therefore, the development of a novel effective therapy for HCC is urgently needed.

The phosphatidylinositol-3-kinase (PI3K)/mammalian target of the rapamycin (mTOR) pathway plays an important role in diverse cellular functions such as proliferation, tumor growth, survival and metabolism $(3,4)$. This pathway is normally regulated by upstream receptor tyrosine kinases. Following the activation of a receptor tyrosine kinase (RTK), $\mathrm{PI} 3 \mathrm{~K}$ is activated and generates the second messenger, phosphatidylinositol 3,4,5-trisphosphate $\left(\mathrm{PIP}_{3}\right)$ (3). $\mathrm{PIP}_{3}$ attracts PDK1 to the plasma membrane and phosphorylates Akt at $\mathrm{Tyr}^{308}$ (5). Full Akt activation requires phosphorylation at $\mathrm{Ser}^{473}$, which is affected by the rapamycin-insensitive mTOR complex (mTORC2 containing rictor) (6). The activated Akt is able to execute a vast number of cellular operations such as cell survival and proliferation through the inhibition of cell cycle inhibitors, pro-apoptotic signals and so on (7). Another mTOR complex, rapamycin-sensitive mTOR complex (mTORC1 containing raptor) stimulates the protein synthesis machinery through the activation of its effector, p70S6K or leads to inactivation of the eukaryotic translation initiation factor $4 \mathrm{E}$ binding protein 1 (4E-BP1), an inhibitor of translation initiation (8). In the PI3K pathway, the phosphatase and tensin homologue (PTEN) acts as a major inhibitor mediating the dephosphorylation of $\mathrm{PIP}_{3}$ (9). Dysregulation of PI3K activity has been reported in human cancers (10-12). The causes include down-regulation or mutation of PTEN and somatic mutation or amplification of PIK3CA, encoding p110 $\alpha$ of the class IA PI3K (13-15). In HCC, somatic mutation of PIK3CA, enhancement of Akt and phosphorylated ribosomal protein $\mathrm{S} 6$ and decrease of PTEN expression have been reported (16-18). These observations suggest that dysregulation of the PI3K/ mTOR pathway may contribute to the survival and growth of HCC and it is therefore considered to be a good molecular target for treatment. 
NVP-BEZ235 is a novel, orally bioavailable inhibitor of pan-class I PI3K/mTOR kinase. It presents inhibition of PI3K activity by competing at its ATP-binding domain. On the mTOR, NVP-BEZ235 inhibits catalytic activity of mTOR, and the inhibition of mTORC1 and mTORC2 has also been observed (19). NVP-BEZ235 has demonstrated anti-tumor effects on various tumor types (19-22). The clinical efficacy of NVP-BEZ235 is currently being evaluated in a phase I/II clinical trial setting in patients with advanced solid malignancies supplemented by patients with advanced breast cancer. However, its effects on HCC have not been documented.

In this study, we investigated the effects of NVP-BEZ235 on HCC cell lines in vitro and in vivo. NVP-BEZ235 inhibited PI3K/mTOR modulators and cell growth of HCC cell lines dose dependently in vitro. Moreover, treatment with NVP-BEZ235 showed suppression of tumor growth without body weight loss in the tumor-bearing mouse model.

\section{Materials and methods}

Cell lines. The human HCC cell line HepG2 was obtained from the Riken Cell Bank, and the PLC/PRF/5, HLE and JHH7 (23) cell lines were obtained from the Health Science Research Resources Bank. All cell lines were cultured in DMEM (Sigma) supplemented with $10 \%$ fetal bovine serum, $2 \mathrm{mM}$ glutamine and $1 \%$ penicillin-streptomycin at $37^{\circ} \mathrm{C}$ in a $5 \% \mathrm{CO}_{2}$ atmosphere.

Compound preparation for in vitro and in vivo studies. NVP-BEZ235 was kindly provided by Novartis Pharma. Rapamycin and LY294002 were purchased from Sigma. For in vitro study, these compounds were dissolved in dimethyl sulfoxide (DMSO) and cells were treated at the indicated final concentrations. The final DMSO concentration was always kept at $0.1 \%$. For in vivo studies, NVP-BEZ235 was dissolved in one volume of NMP (1-methyl-2-pyrrolidone; SigmaAldrich) by sonication $(50 \mathrm{mg} / \mathrm{ml})$, and then nine volumes of polyethylene glycol 300 (Sigma-Aldrich) were added (final concentration $5 \mathrm{mg} / \mathrm{ml})$.

Western blot analysis. For Western blot analyses, the cells $\left(2-4 \times 10^{5}\right)$ were seeded in 6 -well plates. The next day, the medium was discarded and replaced with $2 \mathrm{ml}$ fresh medium and the cells were treated with the compounds at the indicated concentrations for 0-48 h. Floating and adhesion cells were washed twice with ice-cold PBS and then were lysed in the appropriate amount of lysis buffer [50 mM Tris- $\mathrm{HCl}(\mathrm{pH} 7.5)$, $150 \mathrm{mM} \mathrm{NaCl}, 2 \mathrm{mM} \mathrm{MgCl}$, $5 \mathrm{mM}$ sodium pyrophosphate, $50 \mathrm{mM}$ sodium fluoride, $1 \mathrm{mM}$ sodium vanadate, $1 \%$ Nonidet $^{\circledR}$ P-40 and protease inhibitor tablet (Roche Applied Sciences)]. The protein concentration was determined using a $\mathrm{BCA}^{\mathrm{TM}}$ Protein Assay Kit (Pierce). The cell lysates were separated on 7.5-12\% SDS-PAGE gels and transferred to PVDF membranes (Millipore). The membranes were blocked with 5\% non-fat dry milk in TBS-T [10 mM Tris- $\mathrm{HCl}$ (pH 7.4), $150 \mathrm{mM} \mathrm{NaCl}$ and $0.05 \%$ Tween-20] for $1 \mathrm{~h}$ and incubated with the following primary antibodies: anti-p-Akt, anti-Akt, anti-p-p70S6K, anti-p70S6K, anti-p-4E-BP1, anti-PTEN, anti-p110 $\alpha$ (Cell Signaling Technology) and anti- $\beta$-actin (Sigma), followed by reaction with HRP-conjugated secondary antibodies (Jackson
ImmunoResearch). The bands were visualized by ECL (GE Healthcare).

Cell proliferation assay. The cells were seeded in 96-well plates at $2 \times 10^{3}$ cells $/ 100 \mu \mathrm{l}$ per well. On the following day, the cells were treated with various concentrations of NVP-BEZ235, LY294002 or rapamycin for $24 \mathrm{~h}$. After the incubation period, the cells were cultured in the presence of WST- 8 reagent (Dojindo) for $2 \mathrm{~h}$, followed by measurement of absorbance at $450 \mathrm{~nm}$ using a microplate reader (Bio-Rad).

Cell cycle analysis. The cells $\left(1-2 \times 10^{6}\right)$ were seeded in $10-\mathrm{cm}$ culture dishes. After 18-24 h, the medium was discarded and replaced with $10 \mathrm{ml}$ fresh medium and the cells were treated with NVP-BEZ235 at the indicated concentration for $24 \mathrm{~h}$. Floating cells and adhesion cells were collected by trypsinization and washed twice with ice-cold PBS. The cells were fixed in $70 \%$ ethanol at $-20^{\circ} \mathrm{C}$ overnight. After fixation, the cells were washed with PBS and incubated with $50 \mu \mathrm{g} / \mathrm{ml}$ RNaseA (Sigma) for $30 \mathrm{~min}$ at $37^{\circ} \mathrm{C}$. Following incubation, the cells were stained with $50 \mu \mathrm{g} / \mathrm{ml}$ propidium iodide (PI) (Sigma) and evaluated using flow cytometric analysis.

Apoptosis analysis. The cells $\left(1 \times 10^{5}\right)$ were seeded in 6-well culture plates. After 18-24 h, the medium was discarded and replaced with $2 \mathrm{ml}$ fresh medium and the cells were treated with NVP-BEZ235 at the indicated concentration for $48 \mathrm{~h}$. Then, the culture media and cells were collected and centrifuged. After washing, the cells were resuspended in $500 \mu \mathrm{l}$ of $1 \mathrm{X}$ binding buffer, followed by the addition of $5 \mu \mathrm{l}$ of Annexin V-FITC (BioVision) and $5 \mu \mathrm{l}$ of PI (BioVision). The cells were incubated at room temperature for $5 \mathrm{~min}$ in the dark and assessed using flow cytometric analysis.

Tumor xenografts in nude mice. Six- to eight-week-old female BALB/c nude mice $\left(\mathrm{nu}^{+} / \mathrm{nu}^{+}, \mathrm{n}=7\right)$ were purchased from Charles River Laboratories Japan. Mice were maintained under the institutional guidelines set by the Animal Research Committee of the National Cancer Center Hospital East. Mice were housed in air-filtered laminar flow cabinets with a 12-h light cycle and access to food and water ad libitum. JHH7 cells $\left(5 \times 10^{6}\right)$ were subcutaneously injected into the right flank of each mouse. When the tumor volume reached 100 to $200 \mathrm{~mm}^{3}$, the mice were administered $45 \mathrm{mg} / \mathrm{kg}$ NVP-BEZ235 in NMP/ PEG300 (1:9, v/v) or NMP/PEG300 (1:9, v/v) once daily by oral gavage for 11 days. The body weight and the tumor volume were measured from the day of the first treatment. The tumor volume was estimated using the standard formula: $\left(\right.$ length $\mathrm{x}$ width $\left.{ }^{2}\right) / 2$. Tumors were harvested within $1 \mathrm{~h}$ after the last treatment and frozen in liquid nitrogen. The frozen tissues were homogenized using a Multi-Beads Shocker ${ }^{\circledR}$ (Yasui Kikai) and lysed in lysis buffer. The lysates were used for Western blot analysis.

\section{Results}

PI3K/mTOR signaling is activated in HCC cell lines. The expression levels of PI3K/mTOR pathway-related molecules, p-Akt, p-p70S6K, PTEN and p110 $\alpha$, a catalytic site of PI3K, in HCC cell lines were determined by Western blotting (Fig. 1). 


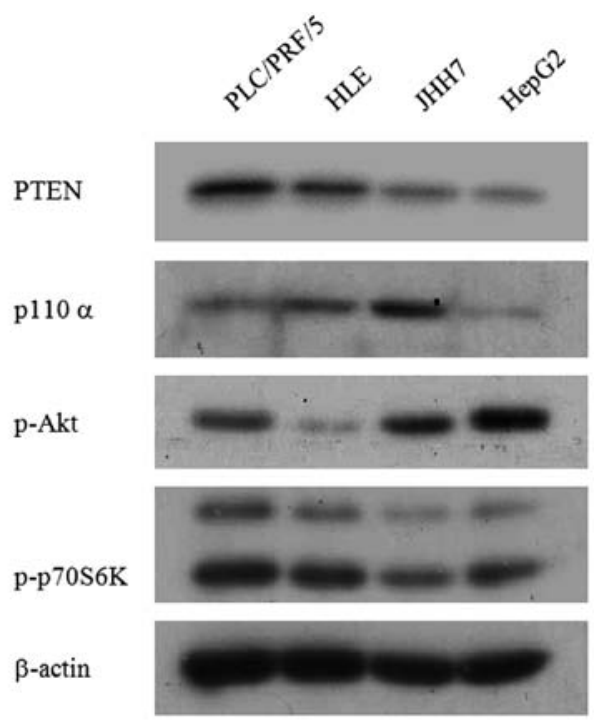

Figure 1. The PI3K/mTOR pathway is activated in HCC cell lines. Western blotting shows the expression level of PTEN, p110 $\alpha$, p-Akt and p-p70S6K in PLC/PRF/5, HLE, JHH7 and HepG2. Cells were cultured in fresh DMEM with $10 \%$ FBS for $12 \mathrm{~h}$. $\beta$-actin was used as an internal control.

The expression level of PTEN was lower in JHH7 and HepG2, and that of p110 $\alpha$ was the highest in $\mathrm{JHH} 7$ among the cell lines. As expected, p-Akt and p-p70S6K were detected in all cell lines. These results suggest that the PI3K/mTOR pathway was activated in these cell lines.

NVP-BEZ235 inhibits the PI3K/mTOR signaling pathway. Next, we evaluated the effect of NVP-BEZ235 on the expression levels of $\mathrm{PI} 3 \mathrm{~K} / \mathrm{mTOR}$ pathway modulators in $\mathrm{HCC}$ cell lines by Western blot analysis. The cells were pretreated with several different concentrations of NVP-BEZ235 for $1 \mathrm{~h}$ and the modulator expression levels were assessed. The PI3K inhibitor LY294002 and the mTORC1 inhibitor rapamycin were used as controls. In all cell lines, the phosphorylation level of Akt and p70S6K was decreased by treatment with NVP-BEZ235 concentations $\geq 30 \mathrm{nM}$ (Fig. 2A). Consistent with the result using NVP-BEZ235, LY294002 inhibited the phosphorylation of both modulators at $10 \mu \mathrm{M}$. In contrast, rapamycin inhibited the phosphorylation of p70S6K but not that of Akt at $100 \mathrm{nM}$.

The inhibitory activity of NVP-BEZ235 on PI3K/mTOR may occur in a competitive and reversible manner. Therefore, we investigated the relevance of the concentration and the duration of NVP-BEZ235 treatment. Time-course experiments were conducted to assess the effects of NVP-BEZ235 at $100 \mathrm{nM}$ (Fig. 2B) and $1 \mu \mathrm{M}$ (Fig. 2C). In PLC/PRF/5 and HLE cells, treatment with $100 \mathrm{nM}$ of NVP-BEZ235 resulted in sustained inhibition of p-p70S6K exceeding $48 \mathrm{~h}$, while p-Akt was inhibited up to $6 \mathrm{~h}$ and its recovery occured at $\sim 12 \mathrm{~h}$ (Fig. 2B). The phosphorylation of Akt was almost completely inhibited for $>48 \mathrm{~h}$ in PLC/PRF/5 and HLE cells incubated with $1 \mu \mathrm{M}$ of NVP-BEZ235 (Fig. 2C). On the contrary, in JHH7 and HepG2 cells, $100 \mathrm{nM}$ of NVP-BEZ235 inhibited p-Akt and p-p70S6K levels for around $6 \mathrm{~h}$, which is shorter than the duration of the inhibition in PLC/PRF/5 and HLE cells (Fig. 2B). However, phosphorylation of Akt and p70S6K was inhibited for $>48 \mathrm{~h}$ in all cells lines treated with $1 \mu \mathrm{M}$ of NVP-BEZ235, except for phosphorylation of Akt in the JHH7 cell line which was observed up to $\sim 12-18$ h (Fig. 2C). In addition, p-4E-BP dose-dependently decreased in all cell lines (Fig. 2D) by NVP-BEZ235 exposure for $18 \mathrm{~h}$.

NVP-BEZ235 inhibited the PI3K/mTOR pathway in a dose-dependent manner. In addition, it is suggested that PLC/ PRF/5 and HLE cells were more sensitive to NVP-BEZ235 than JHH7 and HepG2 cells.

NVP-BEZ235 inhibits cell proliferation through induction of G1 arrest and apoptosis. Since the phosphorylation of Akt and p70S6K was inhibited by NVP-BEZ235, cellular viability and proliferation were evaluated by the WST- 8 assay. Cells were incubated with various concentrations of NVP-BEZ235 for $48 \mathrm{~h}$. Cell growth was inhibited by NVP-BEZ235 in a dose-dependent manner. Growth-inhibition 50\% concentrations $\left(\mathrm{GI}_{50}\right)$ of PLC/PRF/5, HLE, JHH7 and HepG2 cells were $15.2 \mathrm{nM}, 40.6 \mathrm{nM}, 169.2 \mathrm{nM}$ and $>1 \mu \mathrm{M}$, respectively (Fig. 3A). On the other hand, LY294002 and rapamycin showed less antiproliferative activity than NVP-BEZ235, and the $\mathrm{GI}_{50} \mathrm{~s}$ of LY294002 and rapamycin were $>10$ and $>1 \mu \mathrm{M}$, respectively (Fig. 3A).

To determine the mechanism of the antiproliferative activity of NVP-BEZ235, cell cycle analysis and apoptosis analysis were performed using flow cytometric analysis. For cell cycle analysis, the cells were incubated with NVP-BEZ235 for $24 \mathrm{~h}$. The data for PLC/PRF/5 and HLE cells showed that the cells accumulated in the G1 phase of the cell cycle after treatment with NVP-BEZ235 concentrations $\geq 30 \mathrm{nM}$ (Fig. 3B). In contrast, G1 arrest in JHH7 and HepG2 cells was observed at concentrations $>300 \mathrm{nM}$ (Fig. 3B). Consistent with the inhibitory activity on the phosphorylation on Akt and p70S6K, JHH7 and HepG2 cells were less sensitive than PLC/ $\mathrm{PRF} / 5$ and HLE cells.

Furthermore, we investigated the expression level of p27, which typically causes cell arrest in the G1 phase of the cell cycle. HCC cell lines were exposed to NVP-BEZ235 for $18 \mathrm{~h}$ and prepared for Western blotting. The results showed that p27 levels increased in PLC/PRF/5, JHH7 and HepG2 cells, but decreased in HLE cells treated with $1 \mu \mathrm{M}$ NVP-BEZ235 (Fig. 3C).

In addition, we assessed the apoptosis induction activity of NVP-BEZ235 using flow cytometric analysis. Cell lines were incubated with various concentrations of NVP-BEZ235 for $48 \mathrm{~h}$ and stained by Annexin V and PI. Annexin $\mathrm{V}^{+} / \mathrm{PI}^{-}$early apoptotic cells increased in a dose-dependent fashion in PLC/ PRF/5 and HLE. On the contrary, in JHH7 and HepG2 cells, a prominent increase in apoptotic cells was not observed at the concentrations examined (Fig. 3D).

These results suggest that NVP-BEZ235 inhibited cell proliferation through the induction of G1 arrest and apoptosis in a dose-dependent manner, especially in PLC/PRF/5 and HLE cells.

NVP-BEZ235 suppresses tumor growth in vivo. The antitumor activity of NVP-BEZ235 in vivo was investigated in a xenograft model derived from $\mathrm{JHH} 7$ cells, because $\mathrm{JHH} 7$ is the only tumorigenic tumor among the four cell lines. NVP-BEZ235 daily oral administration at $45 \mathrm{mg} / \mathrm{kg}$ for 11 
$\mathbf{A}$

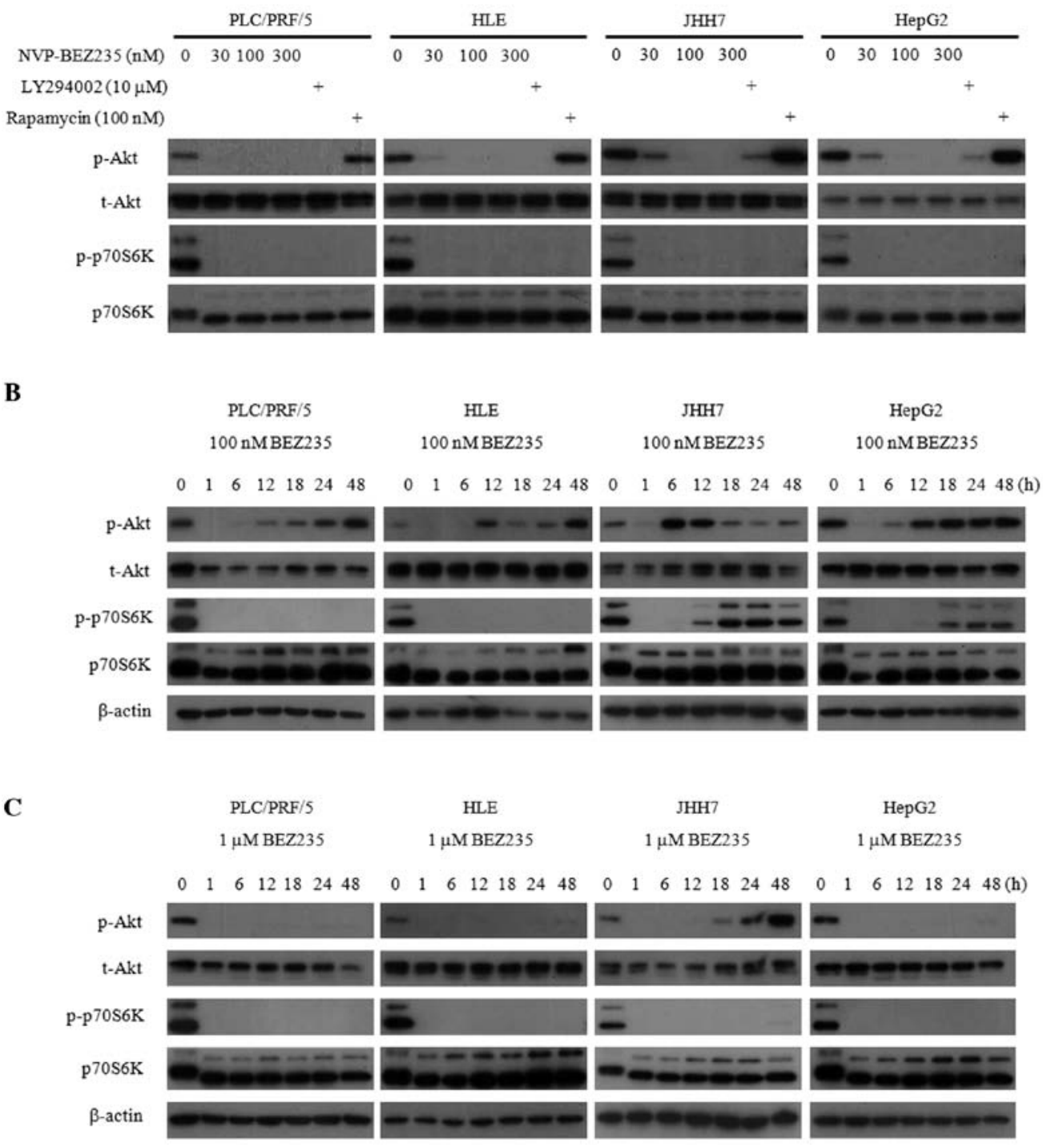

D
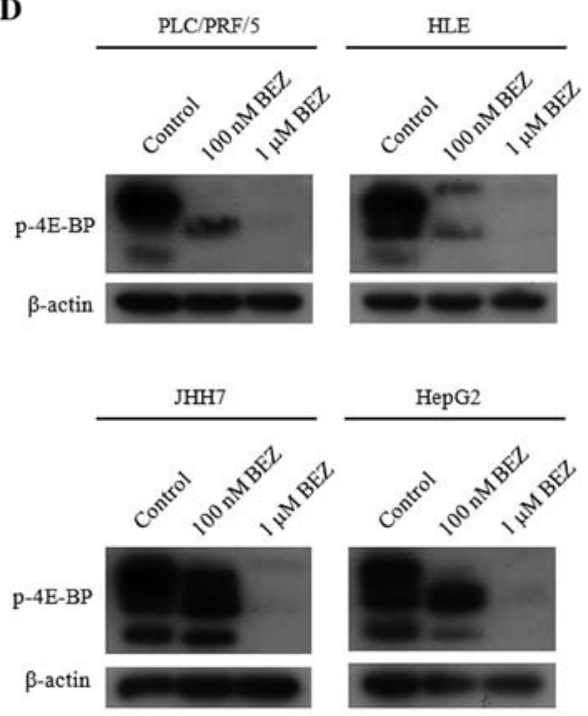

Figure 2. NVP-BEZ235 inhibits the PI3K/mTOR pathway. (A) HCC cell lines (PLC/PRF/5, HLE, JHH7 and HepG2) were treated with NVP-BEZ235, LY294002 or rapamycin for $1 \mathrm{~h}$ and the expression levels of phosphorylated Akt (p-Akt) and phosphorylated p70S6K (p-p70S6K) were analyzed by Western blot analysis. Total Akt (t-Akt) and p70S6K (t-p70S6K) levels are shown as loading controls. (B and C) HCC cell lines were treated with NVP-BEZ235 at $100 \mathrm{nM}(\mathrm{B})$ or $1 \mu \mathrm{M}(\mathrm{C})$ up to $48 \mathrm{~h}$ and the cell lysates were analyzed for p-Akt and p-p70S6K. (D) The HCC cell lines PLC/PRF/5 and HLE were pretreated with NVP-BEZ235 at $100 \mathrm{nM}$ or $1 \mu \mathrm{M}$ for $18 \mathrm{~h}$ and cell lysates were analyzed for $\mathrm{p}-4 \mathrm{E}-\mathrm{BP}$ by Western blot analysis. $\beta$-actin was used as an internal control. days was initiated when a xenograft achieved a volume of $100-200 \mathrm{~mm}^{3}$. Tumor growth was significantly suppressed by NVP-BEZ235, compared with the vehicle-treated controls
$(\mathrm{P}=0.032)$ (Fig. 4A). There were no statistical differences between the treated and control groups; loss of body weight occurred in both the control and treatment groups (Fig. 4B), 
A
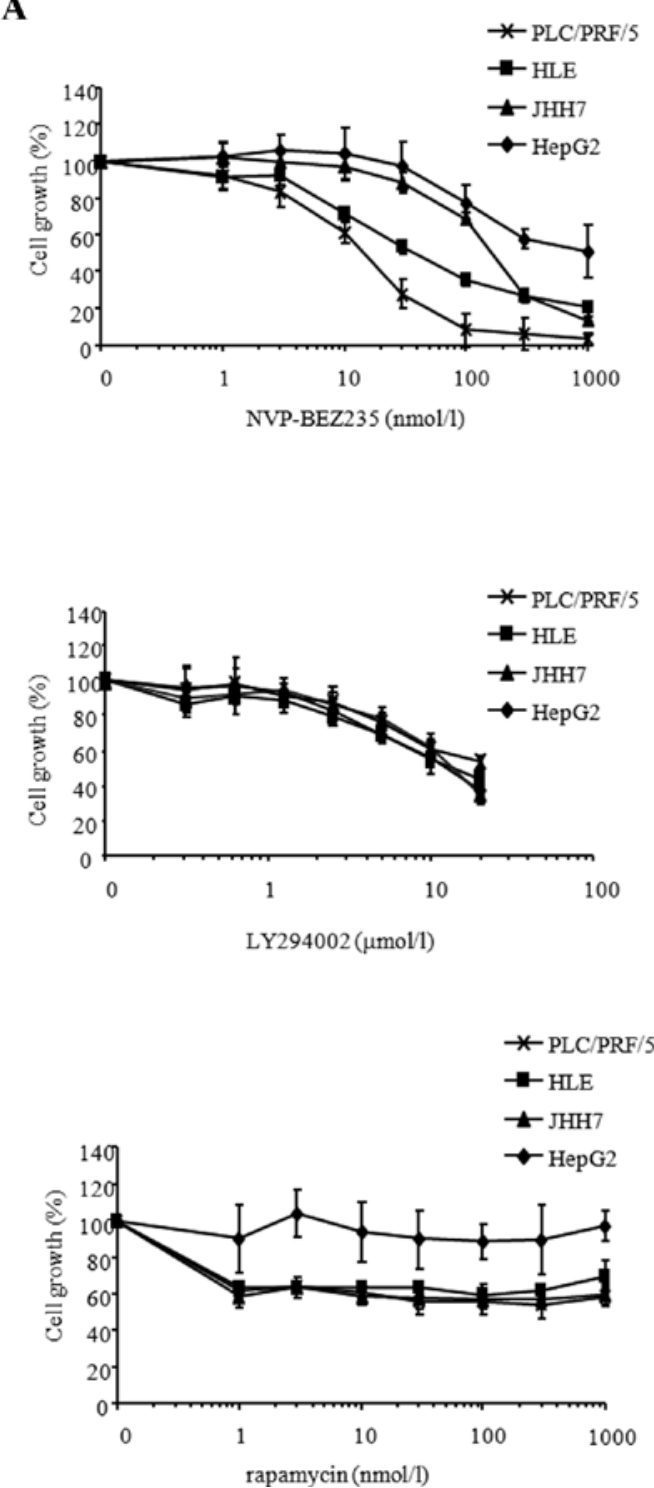

B

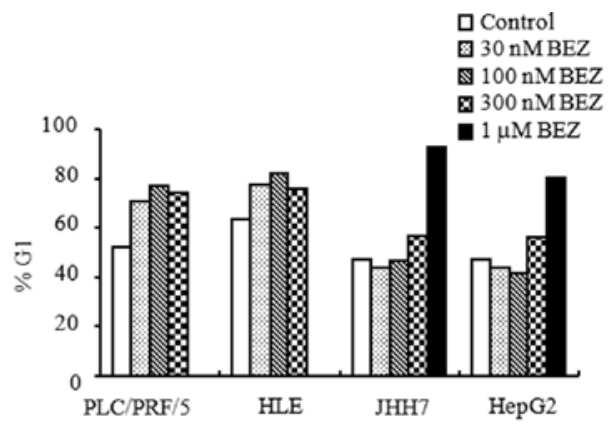

C

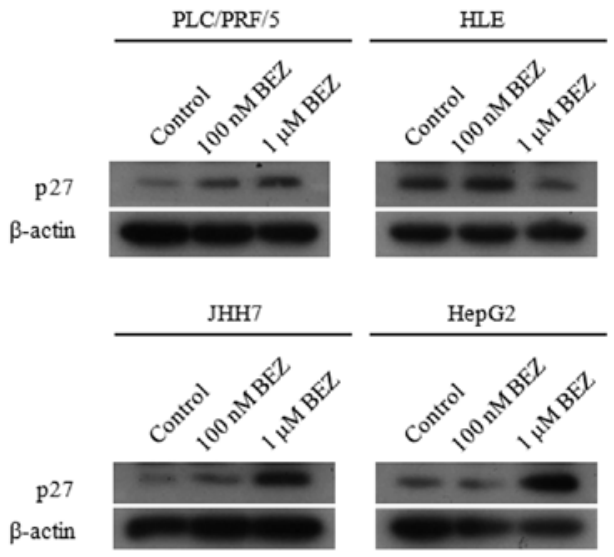

D

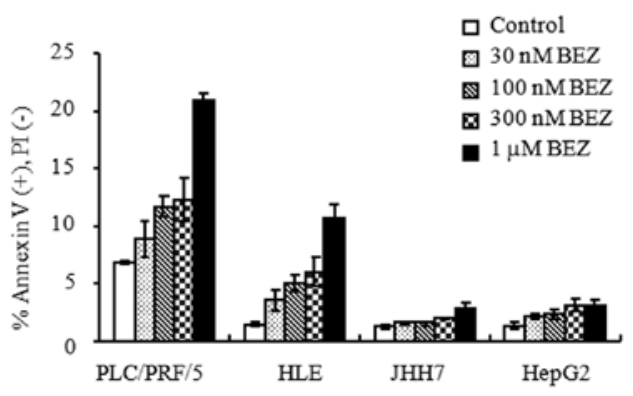

Figure 3. NVP-BEZ235 blocks cell proliferation and induces G1 cell cycle arrest and apoptosis in HCC cell lines. (A) HCC cells (2x10 $3 /$ well) were incubated with various concentrations of NVP-BEZ235, LY294002 or rapamycin and cell viability was determined after 48 h by the WST-8 assay. The data are presented as the percent of viable cells vs. non-treated cells $(\mathrm{n}=6)$. (B) The cells were treated with various concentrations of NVP-BEZ235 for $24 \mathrm{~h}$, and cell cycle analysis was performed by PI staining. The data show the percentage of the G1 phase population in each cell line. (C) The cells were treated with $100 \mathrm{nM}$ or $1 \mu \mathrm{M}$ of NVP-BEZ235 for $18 \mathrm{~h}$, and lysates were analyzed by Western blot analysis for p27. $\beta$-actin was used as an internal control. (D) Cells (1x10\%/well) were treated with various concentrations of NVP-BEZ235. After $48 \mathrm{~h}$, the cells were harvested and stained with Annexin V and PI. Annexin $\mathrm{V}^{+} / \mathrm{PI}^{-}$cells were detected using flow cytometric analysis. The percentage of Annexin $\mathrm{V}^{+} / \mathrm{PI}^{-}$(early apoptotic) cells is shown.

which may have been due to the tumor. At the end of the experiment, we measured the level of p-Akt in tumors excised from the mice at $1 \mathrm{~h}$ post-drug administration by Western blot analysis. The phosphorylation of Akt was decreased in the treatment group (Fig. 4C). These results indicate that NVP-BEZ235 suppresses HCC tumor growth through the down-regulation of PI3K in vivo.

\section{Discussion}

Dysregulation of growth factors, receptors and their downstream signaling pathway components have been reported in HCC (1). We focused on the PI3K/mTOR pathway and hypothesized that it might be a candidate therapeutic target in HCC.
NVP-BEZ235 reduces the kinase activity of both PI3K and mTOR (19). Previous reports show the effect of NVP-BEZ235 on several types of tumors (19-22). In this study, we examined the efficacy of NVP-BEZ235 against HCC cell lines.

Indeed, the PI3K/mTOR pathway is activated in $\mathrm{HCC}$ cell lines. NVP-BEZ235 completely inhibited the phosphorylation of Akt and p70S6K in all cell lines treated with NVP-BEZ235 for $1 \mathrm{~h}$ at $100 \mathrm{nM}$. However, time-course experiments revealed a difference in sensitivity to NVP-BEZ235 among the cell lines. JHH7 and HepG2 cells recovered phosphorylation of Akt and p70S6K earlier than PLC/PRF/5 and HLE cells. JHH7 and HepG2 cells expressed a low level of PTEN that acts as an inhibitor of the PI3K pathway. In addition, the expression level of p110 $\alpha$, a catalytic site of PI3K, was up-regulated to a greater 


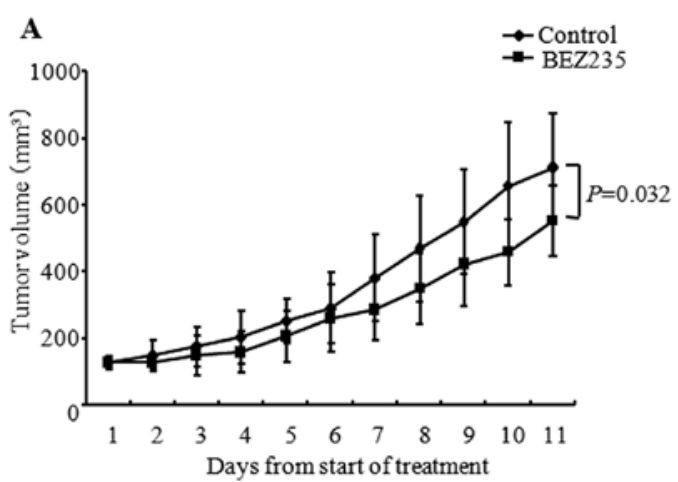

B

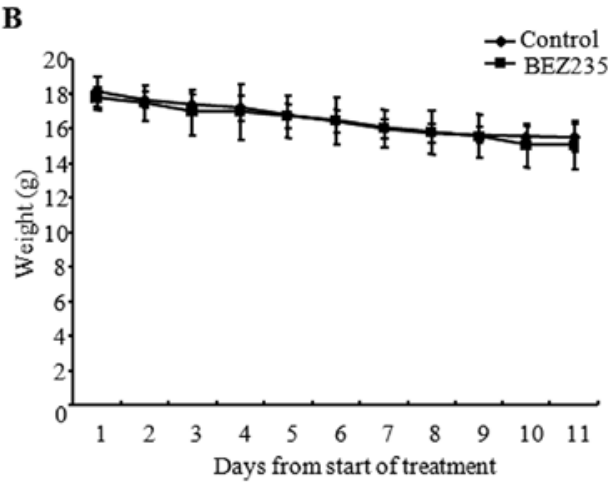

C

\begin{tabular}{|c|c|c|c|c|c|c|}
\hline & \multicolumn{3}{|c|}{ Control } & \multicolumn{3}{|c|}{ BEZ235 } \\
\hline & 1 & 2 & 3 & 1 & 2 & 3 \\
\hline p-Akt & & & & & - & $m$ \\
\hline -actin & & & & & & \\
\hline
\end{tabular}

Figure 4. Effect of NVP-BEZ235 on tumor growth in vivo. (A and B) JHH7 tumor-bearing mice were treated with NVP-BEZ235 $(45 \mathrm{mg} / \mathrm{kg})$ or with the vehicle control once per day for 11 days $(n=7)$. Tumor volume (A) and body weight (B) were recorded during the course of the experiment. (C) One hour after the last treatment, the $\mathrm{JHH} 7$ xenograft was removed and the expression level of p-Akt was analyzed by Western blot analysis.

degree in JHH7 than in the others. These factors may have contributed to the earlier phosphorylation recovery of Akt and p70S6K in JHH7 and HepG2 cells.

NVP-BEZ235 inhibited cell proliferation in a dose-dependent manner. In the cell proliferation assay, consistent with the time-course experiments, PLC/PRF/5 and HLE cells showed higher sensitivity to NVP-BEZ235; the $\mathrm{GI}_{50}$ s were $<50 \mathrm{nM}$. On the contrary, JHH7 and HepG2 showed lower sensitivity; the $\mathrm{GI}_{50} \mathrm{~s}$ were $>150 \mathrm{nM}$. Next, we compared the antiproliferative activity of NVP-BEZ235 with the PI3K inhibitor LY294002. It was interesting that dual inhibition of PI3K and mTOR by NVP-BEZ235 was more effective than treatment with the PI3K inhibitor or the mTORC1 inhibitor alone.

In addition, the results of cell cycle analysis and apoptosis assay showed different tendencies between the high-sensitivity group, PLC/PRF/5 and HLE, and the low-sensitivity group, JHH7 and HepG2 cells. G1 arrest and apoptosis were induced by a lower concentration of NVP-BEZ235 (<30 nM) in PLC/ PRF/5 and HLE cells. On the contrary, JHH7 and HepG2 cells required a high concentration of NVP-BEZ235 (>300 nM) for G1 arrest; moreover, apoptosis was not significantly induced. These results suggest that the antiproliferation was due to G1 arrest and apoptosis in the high-sensitivity group, but only G1 arrest in the low-sensitivity group. In addition, NVP-BEZ235 inhibited the phosphorylation of p70S6K and 4EBP through the inhibition of mTOR. The phosphorylation of these molecules results in protein synthesis. This result may also have contributed to the antiproliferative activity of NVP-BEZ235. The p27 expression level was analyzed to investigate G1 arrest. The p27 expression level was higher than that of the control cells in the treated PLC/PRF/5, JHH7 and HepG2 cells, but not in HLE cells. There are other molecules regulating the cell cycle that are related to the PI3K/mTOR pathway; therefore, further study of cell-cycle molecules such as p21 is required.

Moreover, it remains unclear why apoptosis was not significantly induced in JHH7 and HepG2 cells. In JHH7 and HepG2 cells, phosphorylation of Akt was significantly inhibited, at least at $1 \mu \mathrm{M}$; indeed, cell cycle arrest was observed at $1 \mu \mathrm{M}$. NVP-BEZ235 induced apoptosis through the inhibition of PI3K/mTOR, which is located upstream from pro- or anti-apoptotic molecules. Therefore, if downstream molecules that regulate apoptosis were dysregulated, NVP-BEZ235 may not be able to fully induce apoptosis. Indeed, $\mathrm{HCC}$ has been reported to overexpress $\mathrm{Bcl}-\mathrm{x}_{\mathrm{L}}$, an anti-apoptotic member of the Bcl-2 family (24), and to down-regulate pro-apoptotic members, $\mathrm{Bcl}-\mathrm{x}_{\mathrm{S}}$ and Bax, with dysfunction in the $\mathrm{p} 53$ pathway (25). Therefore, further study is required on the dysregulation of pro- or anti-apoptotic molecules such as $\mathrm{Bcl}-\mathrm{x}_{\mathrm{L}}$, Bax or $\mathrm{Bcl}-\mathrm{X}_{\mathrm{S}}$ in $\mathrm{JHH} 7$ and HepG2.

NVP-BEZ235 significantly suppressed tumor growth in vivo in $\mathrm{JHH7}$, which was less sensitive to NVP-BEZ235 treatment in vitro. Moreover, there was no significant difference in the loss of body weight between the treated and control groups. These results suggest that NVP-BEZ235 is effective and tolerable in HCC therapy.

In summary, this study demonstrated that NVP-BEZ235 inhibits the PI3K/mTOR pathway in HCC cell lines both in vitro and in vivo. NVP-BEZ235 is a potential therapeutic option for the treatment of HCC. However, HCC cell lines showed slightly lower sensitivity to NVP-BEZ235 in this study compared to other cancer cell lines in previous reports (19-22). Further investigation is needed to clarify the effectiveness of NVP-BEZ235 in HCC.

\section{Acknowledgements}

This study was supported in part by Novartis Pharma. This sponsor is not responsible for the data collection and analysis, interpretation of the data or preparation of the manuscript.

\section{References}

1. El-Serag HB and Rudolph KL: Hepatocellular carcinoma: epidemiology and molecular carcinogenesis. Gastroenterology 132: 2557-2576, 2007.

2. Sherman M: Hepatocellular carcinoma: epidemiology, surveillance, and diagnosis. Semin Liver Dis 30: 3-16, 2010.

3. Cantley LC: The phosphoinositide 3-kinase pathway. Science 296: 1655-1657, 2002.

4. Vivanco I and Sawyers CL: The phosphatidylinositol 3-kinase AKT pathway in human cancer. Nat Rev Cancer 2: 489-501, 2002. 
5. Alessi DR, James SR, Downes CP, et al: Characterization of a 3-phosphoinositide-dependent protein kinase which phosphorylates and activates protein kinase Balpha. Curr Biol 7: 261-269, 1997.

6. Sarbassov DD, Ali SM, Sengupta S, et al: Prolonged rapamycin treatment inhibits mTORC2 assembly and Akt/PKB. Mol Cell 22: 159-168, 2006.

7. Manning BD and Cantley LC: AKT/PKB signaling: navigating downstream. Cell 129: 1261-1274, 2007.

8. Foster KG and Fingar DC: Mammalian target of rapamycin (mTOR): conducting the cellular signaling symphony. J Biol Chem 285: 14071-14077, 2010.

9. Sansal I and Sellers WR: The biology and clinical relevance of the PTEN tumor suppressor pathway. J Clin Oncol 22: 2954-2963, 2004.

10. Phillips WA, St Clair F, Munday AD, Thomas RJ and Mitchell CA Increased levels of phosphatidylinositol 3-kinase activity in colorectal tumors. Cancer 83: 41-47, 1998.

11. Benistant C, Chapuis $\mathrm{H}$ and Roche S: A specific function for phosphatidylinositol 3-kinase alpha (p85alpha-p110alpha) in cell survival and for phosphatidylinositol 3-kinase beta (p85alphap110beta) in de novo DNA synthesis of human colon carcinoma cells. Oncogene 19: 5083-5090, 2000.

12. Yuan ZQ, Sun M, Feldman RI, et al: Frequent activation of AKT2 and induction of apoptosis by inhibition of phosphoinositide3-OH kinase/Akt pathway in human ovarian cancer. Oncogene 19: 2324-2330, 2000.

13. Cantley LC and Neel BG: New insights into tumor suppression: PTEN suppresses tumor formation by restraining the phosphoinositide 3-kinase/AKT pathway. Proc Natl Acad Sci USA 96: 4240-4245, 1999.

14. Samuels Y, Wang Z, Bardelli A, et al: High frequency of mutations of the PIK3CA gene in human cancers. Science 304: 554, 2004

15. Shayesteh L, Lu Y, Kuo WL, et al: PIK3CA is implicated as an oncogene in ovarian cancer. Nat Genet 21: 99-102, 1999.

16. Lee JW, Soung YH, Kim SY, et al: PIK3CA gene is frequently mutated in breast carcinomas and hepatocellular carcinomas Oncogene 24: 1477-1480, 2005.
17. $\mathrm{Hu} \mathrm{TH}$, Huang $\mathrm{CC}$, Lin $\mathrm{PR}$, et al: Expression and prognostic role of tumor suppressor gene PTEN/MMAC1/TEP1 in hepatocellular carcinoma. Cancer 97: 1929-1940, 2003

18. Zhou L, Huang Y, Li J and Wang Z: The mTOR pathway is associated with the poor prognosis of human hepatocellular carcinoma. Med Oncol 27: 255-261, 2010.

19. Maira SM, Stauffer F, Brueggen J, et al: Identification and characterization of NVP-BEZ235, a new orally available dual phosphatidylinositol 3-kinase/mammalian target of rapamycin inhibitor with potent in vivo antitumor activity. Mol Cancer Ther 7: 1851-1863, 2008

20. Baumann P, Mandl-Weber S, Oduncu F and Schmidmaier R: The novel orally bioavailable inhibitor of phosphoinositol-3-kinase and mammalian target of rapamycin, NVP-BEZ235, inhibits growth and proliferation in multiple myeloma. Exp Cell Res 315: 485-497, 2009.

21. Cao P, Maira SM, Garcia-Echeverria C and Hedley DW: Activity of a novel, dual PI3-kinase/mTOR inhibitor NVP-BEZ235 against primary human pancreatic cancers grown as orthotopic xenografts. Br J Cancer 100: 1267-1276, 2009.

22. Marone R, Erhart D, Mertz AC, et al: Targeting melanoma with dual phosphoinositide 3-kinase/mammalian target of rapamycin inhibitors. Mol Cancer Res 7: 601-613, 2009.

23. Fujise K, Nagamori S, Hasumura S, et al: Integration of hepatitis $\mathrm{B}$ virus DNA into cells of six established human hepatocellular carcinoma cell lines. Hepatogastroenterology 37: 457-460, 1990.

24. Beerheide W, Tan YJ, Teng E, Ting AE, Jedpiyawongse A and Srivatanakul P: Down-regulation of proapoptotic proteins Bax and $\mathrm{Bcl}-\mathrm{X}(\mathrm{S})$ in $\mathrm{p} 53$ overexpressing hepatocellular carcinomas. Biochem Biophys Res Commun 273: 54-61, 2000.

25. Takehara T, Liu X, Fujimoto J, Friedman SL and Takahashi H: Expression and role of Bcl-xL in human hepatocellular carcinomas. Hepatology 34: 55-61, 2001. 